\title{
Stochastic Analysis, Stochastic Systems, and Applications to Finance
}




\section{Stochastic Analysis, Stochastic Systems, and Applications to Finance}

Edited by

\section{Allanus Tsoi}

University of Missouri, Columbia, USA

David Nualart

University of Kansas, USA

George Yin

Wayne State University, Michigan, USA

\section{$\|=$ World Scientific}


This page is intentionally left blank 
Published by

World Scientific Publishing Co. Pte. Ltd.

5 Toh Tuck Link, Singapore 596224

USA office: 27 Warren Street, Suite 401-402, Hackensack, NJ 07601

UK office: 57 Shelton Street, Covent Garden, London WC2H 9HE

\section{British Library Cataloguing-in-Publication Data}

A catalogue record for this book is available from the British Library.

\section{STOCHASTIC ANALYSIS, STOCHASTIC SYSTEMS, AND APPLICATIONS TO FINANCE}

Copyright $\odot 2011$ by World Scientific Publishing Co. Pte. Ltd.

All rights reserved. This book, or parts thereof, may not be reproduced in any form or by any means, electronic or mechanical, including photocopying, recording or any information storage and retrieval system now known or to be invented, without written permission from the Publisher.

For photocopying of material in this volume, please pay a copying fee through the Copyright Clearance Center, Inc., 222 Rosewood Drive, Danvers, MA 01923, USA. In this case permission to photocopy is not required from the publisher.

ISBN-13 978-981-4355-70-4

ISBN-10 981-4355-70-4

Printed in Singapore. 


\section{Contents}

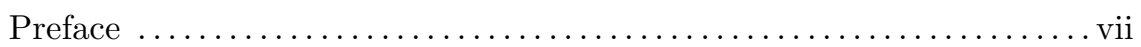

Contributors and Addresses $\ldots \ldots \ldots \ldots \ldots \ldots \ldots \ldots \ldots \ldots \ldots \ldots$ ix

\section{Part I. Stochastic Analysis and Systems}

1. Multidimensional Wick-Itô Formula for Gaussian Processes ....... 3 D. Nualart and S. Ortiz-Latorre

2. Fractional White Noise Multiplication $\ldots \ldots \ldots \ldots \ldots \ldots \ldots \ldots \ldots \ldots$ A. H. Tsoi

3. Invariance Principle of Regime-Switching Diffusions .43 C. Zhu and G. Yin

\section{Part II. Finance and Stochastics}

4. Real Options and Competition

A. Bensoussan, J. D. Diltz, and S. R. Hoe

5. Finding Expectations of Monotone Functions of Binary Random Variables by Simulation, with Applications to Reliability, Finance, and Round Robin Tournaments

M. Brown, E. A. Peköz, and S. M. Ross

6. Filtering with Counting Process Observations and Other

Factors: Applications to Bond Price Tick Data

X. Hu, D. R. Kuipers, and Y. Zeng 
7. Jump Bond Markets Some Steps towards General Models in Applications to Hedging and Utility Problems .............. 145

M. Kohlmann and D. Xiong

8. Recombining Tree for Regime-Switching Model: Algorithm and Weak Convergence

R. H. Liu

9. Optimal Reinsurance under a Jump Diffusion Model S. Luo

10. Applications of Counting Processes and Martingales in Survival Analysis ....................................231

J. Sun

11. Stochastic Algorithms and Numerics for Mean-Reverting Asset Trading

Q. Zhang, C. Zhuang, and G. Yin 


\section{Preface}

This volume contains 11 chapters. It is an expanded version of the papers presented at the first Kansas-Missouri Winter School of Applied Probability, which was organized by Allanus Tsoi and was held at the University of Missouri, February 14 and 15, 2008. It brought together researchers from different parts of the country to review and to update the recent advances, and to identify future directions in the areas of applied probability, stochastic processes, and their applications.

After the successful conference was over, there was a strong support of publishing the papers delivered in the conference as an archival volume. Based on the support, we began the preparation on this project. In addition to papers reported at the conference, we have invited a number of colleagues to contribute additional papers.

As an archive, this volume presents some of the highlights of the conference, as well as some of most recent developments in stochastic systems and applications. This book is naturally divided into two parts. The first part contains some recent results in stochastic analysis, stochastic processes and related fields. It explores the Itô formula for multidimensional Gaussian processes using the Wick integral, introduces the notion of fractional white noise multiplication, and discusses the LaSalle type of invariance principles for hybrid switching diffusions. The second part of the book is devoted to financial mathematics, insurance models, and applications. Included here are optimal investment policies for irreversible capital investment projects under uncertainty in monopoly and Stackelberg leader-follower environments, 
finding expectations of monotone functions of binary random variables by simulation, with applications to reliability, finance, and round robin tournaments, jump bond markets with general models in applications to hedging and utility problems, algorithm and weak convergence for recombining tree in a regime-switching model, applications of counting processes and martingales in survival analysis, extended filtering micro-movement model with counting process observations and applications to bond price tick data, optimal reinsurance for a jump diffusion model, recursive algorithms and numerical studies for mean-reverting asset trading.

Without the encouragement and assistance of many colleagues, this volume would have never come into being. We thank all the authors of this volume, and all of the speakers of the conference for their contributions. The financial support provided by the University of Missouri for this conference is also greatly acknowledged.

Allanus Tsoi Columbia, Missouri David Nualart Lawrence, Kansas George Yin Detroit, Michigan 


\section{Contributors and Addresses}

- Alain Bensoussan, School of Management, University of Texas at Dallas, Richardson, TX 75083-0688, USA. \& The Hong Kong Polytechnic University, Hong Kong. Email: alain.bensoussan@utdallas. edu

- Mark Brown, Department of Mathematics, City College, CUNY, New York, NY, USA. Email: cybergarf@aol.com

- J. David Diltz, Department of Finance and Real Estate, The University of Texas at Arlington, Arlington, TX 76019, USA. Email: diltz@uta.edu

- SingRu Hoe, School of Management, University of Texas at Dallas, Richardson, TX 75083-0688, USA. Email: celinehoe@utdallas.edu

- Xing Hu, Department of Economics, Princeton University, Princeton, 08544, USA. Email: xinghu@princeton.edu

- Michael Kohlmann, Department of Mathematics and Statistics, University of Konstanz, D-78457, Konstanz, Germany. Email: michael.kohlmann@uni-konstanz.de

- David R. Kuipers, Department of Finance, Henry W. Bloch School of Business and Public Administration, University of Missouri at Kansas City, Kansas City, MO 64110, USA. Email: kuipersd@umkc.edu

- Ruihua Liu, Department of Mathematics, University of Dayton, 300 College Park, Dayton, OH 45469-2316, USA. Email: ruihua.liu@notes.udayton.edu 
- Shangzhen Luo, Department of Mathematics, University of Northern Iowa, Cedar Falls, Iowa, 50614-0506, USA. Email: luos@uni.edu

- David Nualart, Department of Mathematics, University of Kansas, Lawrence, KS 66045, USA. Email: nualart@math.ku.edu

- Salvador Ortiz-Latorre, Departament de Probabilitat, Lògica i Estadística, Universitat de Barcelona, Gran Via 585, 08007 Barcelona, Spain. Email: sortiz@ub.edu

- Erol A. Pekoz, School of Management, Boston University, 595 Commonwealth Avenue, Boston, MA 02215, USA. Email: pekoz@bu.edu

- Sheldon M. Ross, Department of Industrial and Systems Engineering, University of Southern California, Los Angeles, CA 90089, USA. Email: smross@usc.edu

- Jianguo Sun, Department of Statistics, University of Missouri, USA. Email: sunj@missouri.edu

- Allanus Hak-Man Tsoi, Department of Mathematics, University of Missouri, Columbia, MO 65211, USA. Email: tsoia@missouri.edu

- Dewen Xiong, Department of Mathematics, Shanghai Jiaotong University, Shanghai 200240, People's Republic of China. Email: xiongdewen@sjtu.edu.cn

- George Yin, Department of Mathematics, Wayne State University, Detroit, MI 48202, USA. Email: gyin@math.wayne.edu

- Yong Zeng, Department of Mathematics and Statistics, University of Missouri at Kansas City, Kansas City, MO 64110, USA. Email: zengy@umkc.edu

- Qing Zhang, Department of Mathematics, University of Georgia, Athens, GA 30602, USA. Email: qingz@math.uga.edu

- Chao Zhu, Department of Mathematical Sciences, University of Wisconsin-Milwaukee, Milwaukee, WI 53201, USA. Email: zhu@uwm.edu

- Chao Zhuang, Marshall School of Business, University of Southern California, Los Angeles, CA 90089, USA. Email: czhuang@usc.edu 